\title{
MISMAS AULAS, DIFERENTES DESTINOS. \\ LOS ESTUDIOS UNIVERSITARIOS COMO FACTOR DE ASCENSO EN LAS CARRERAS PÚBLICAS
}

\author{
Rodolfo Aguirre Salvador \\ Universidad Nacional Autónoma de México
}

$\mathrm{E}_{\text {co tenemos ya estudios sobre su gobierno, }{ }^{1} \text { su estruc- }}$ tura docente y corporativa, ${ }^{2}$ los números de sus diferentes poblaciones ${ }^{3}$ y los patrones de carrera de sus graduados. ${ }^{4}$ Sin embargo, falta mucho por conocer de su historia social. Ahondar en esta vertiente posibilita entender las facilidades o los límites que la sociedad ofrecía a los grupos o

Fecha de recepción: 16 de enero de 2015

Fecha de aceptación: 21 de julio de 2015

${ }^{1}$ Ramírez González, “La Real Universidad de México”, pp. 83-94. González González, "Legislación y poderes”. Pérez Puente, "El surgimiento de una universidad".

2 Ramírez González y Pavón Romero, "De estudiantes a catedráticos”, pp. 279-290.

3 Peset, Mancebo y Peset, “El recuento de los libros”. Pavón Romero, "Universitarios y universidad".

${ }^{4}$ Aguirre Salvador, Por el camino y El mérito y la estrategia. Menegus (coord.), Universidad y sociedad. Pavón Romero y Ramírez GonzÁLEZ (comps.), El catedrático novohispano. 
estamentos sociales bajos para acceder a los estudios mayores e iniciar una trayectoria pública. Este trabajo se valdrá de la documentación resguardada en el archivo de la Real Universidad de México para tal efecto, centrándose en estudiar hasta qué punto el paso por sus aulas incidía en el ascenso social de los estudiantes.

A medida que transcurrieron los años y las décadas, en Nueva España hubo cada vez más demanda de estudios y grados de ciertos sectores de la sociedad, sobre todo a partir del siglo Xvir. Con el aumento de las ciudades y villas de españoles, así como de las haciendas, en donde también comenzaron a establecerse núcleos importantes de familias, nuevas generaciones de jóvenes buscaron el camino de las letras como una forma de ascender también socialmente. Simultáneamente, familias no españolas pero con posibilidades de costear estudios a sus hijos también se hicieron presentes en el ámbito educativo. Para la segunda mitad de ese siglo se advierte en el estudiantado universitario una mayor diversidad social respecto a décadas anteriores. Esto es importante porque las expectativas de cada alumno estaba también en función del estamento o el rango social de origen; es decir: ¿ ¿e dónde provenían y a dónde aspiraban llegar? Así, los estudios podín tener diferentes significados o motivaciones para un hijo de cacique, de un comerciante pequeño de un pueblo o villa, de un almacenero del Consulado de México, de un oidor o de un caballero de la Orden Militar de Santiago.

DE LA UNIVERSIDAD IDEAL A LA DIVERSIDAD SOCIAL

Desde su fundación en 1551, la Universidad de México se identificó con el proyecto social y político de los colonizadores 
españoles. ${ }^{5}$ En el transcurso del siglo xviI, la corporación universitaria creció y se consolidó, identificándose a sí misma como un cuerpo de españoles americanos distinguidos, provenientes de familias nobles, honorables, limpias de sangre y alejados de oficios viles o mecánicos. ${ }^{6}$ En la segunda mitad de ese siglo se hizo un balance de lo que había sido la universidad hasta entonces, a raíz de la puesta en marcha de las nuevas constituciones elaboradas por el visitador real Juan de Palafox y Mendoza en la década de 1640. En 1668, con motivo de la confirmación real y publicación de las mismas, el rector fray Marcelino de Solís definió a los doctores de la universidad como: "[...] sujetos singularísimos en puestos, letras, virtud y prendas [...]". El discurso de los dirigentes de la Universidad iba encaminado a convencer a la sociedad, a las autoridades y a la corona, sobre su distinguida conformación. ${ }^{7}$

En el siglo XviII, otros escritos del claustro universitario insistieron en el mismo discurso, como el de $1777,{ }^{8}$ en respuesta a la nueva política anticriolla sobre nombramientos eclesiásticos. ${ }^{9}$ No obstante, ese discurso se refería a la élite

${ }^{5}$ Menegus, "Dos proyectos”, pp. 83-89. En el Tercer Concilio mexicano, de 1585, y después, en 1588, Felipe II dejaba una posibilidad para indios y mestizos bien preparados, de nacimiento legítimo y vida virtuosa. Véase García y García, III Concilio y Directorio, lib. 1, tít. IV, "De la vida, fama y costumbres de los que se han de ordenar", parágrafo III: "Los indios y los mestizos no sean admitidos a los sagrados órdenes sino con la mayor y más cuidadosa elección”. La cédula de 1588 en Recopilación de leyes, tomo primero, f. 32r.

${ }^{6}$ Chocano Mena, La fortaleza docta, pp. 157-182.

7 Aguirre Salvador, El mérito y la estrategia, pp. 30-34.

8 Aguirre Salvador, El mérito y la estrategia, pp. 50-64.

9 AGN, Universidad, 25, ff. 199v.-207v. 
académica y gobernante de la corporación universitaria: los doctores y catedráticos, quienes se atribuían la máxima representación de la institución. ${ }^{10}$ Ellos eran descendientes de comerciantes, funcionarios, hacendados acomodados y de familias aristocráticas que veían en la universidad y sus carreras un destino digno de sus aspiraciones. Quedaban fuera cientos de estudiantes y bachilleres que, a pesar de los obstáculos económicos y sociales que tenían que enfrentar cotidianamente, se esforzaban por conseguir al menos un grado de bachiller que les diera alguna posibilidad de ascenso social. ¿Es qué acaso ellos no eran integrantes de la Real Universidad de México? Formalmente sí, pero en la práctica no participaban de su gobierno, ni de sus decisiones ni de sus beneficios.

Sin embargo, más allá de esa concepción de universidad ideal de la élite académica, las transformaciones sociales vividas en Nueva España durante el siglo XviI tuvieron repercusión en corporaciones que, como esa institución, defendían un proyecto de sociedad dirigido por la república de los españoles. En ese proyecto, los estudios mayores no estaban pensados para los indios ni para los nuevos grupos mestizos. Si bien en 1551 la cédula de fundación de la Universidad había señalado expresamente la aceptación de los indios como vasallos libres del rey, su catástrofe demográfica y la nueva política tributaria de Felipe II de la segunda mitad del siglo xvi, que implicó el desgaste de la antigua nobleza indígena, les impidieron estar en posibilidad de aspirar a los estudios y los grados.

${ }^{10}$ En ello concuerda también Gonzalbo, Familia y orden colonial, pp. 226-227, para quien la defensa de la pureza de sangre la hacía una minoría criolla, proporcional al mestizaje evidente de la sociedad hacia 1771. 
En el siglo XviI, la Universidad y sus estudiantes ya eran diferentes: una corporación más compleja y amplia, cuyos miembros provenían de un mayor abanico social. En la época del virrey Cerralbo un incidente en la facultad de Medicina, en 1634, abrió una discusión sobre la presencia de estudiantes mestizos y mulatos en las escuelas universitarias, surgida por la molestia de algunos estudiantes criollos opuestos a tal permiso. ${ }^{11}$ Esta situación era reflejo de la nueva conformación de la sociedad novohispana, en donde un mayor número de grupos sociorraciales, estamentales y corporativos pugnaban por ocupar una mejor posición. Por entonces, ninguna de las normas que regían a la Universidad se había ocupado de tal asunto, por lo cual el virrey ordenó permitir a los estudiantes impugnados la asistencia a los cursos. Y es que, antes de las constituciones palafoxianas de 1645 , que regirían hasta el fin de la colonia a la Universidad, lo que más se acercó a una revisión de la calidad social fue la obligación de los licenciados y doctores, la élite académica, de presentar testigos sobre su vida y costumbres ante el secretario de la Universidad. ${ }^{12}$ Tal norma la hallamos vigente hasta la década de 1660, cuando se añade la obligación de comprobar su limpieza de sangre. ${ }^{13}$ Mas respecto al control de los estudiantes no hubo por entonces algo parecido.

${ }_{11}$ AGN, Universidad, 40, ff. 172 ss.

${ }^{12}$ Es muy probable que tal costumbre se haya originado a raíz del Concilio de Trento, que pedía tal tipo de información a los futuros clérigos. Véase sobre todo la sesión XXIII, "El sacramento del orden”, en especial el capítulo V: "Qué circunstancias deban tener los que se quieren ordenar", y capítulo VII: "El examen de los ordenandos".

13 AGN, Universidad, 263, Grados mayores de Cánones, 1662-1699, f. 42. 
No obstante, es de suponer que en los años siguientes hubo más discusiones y fricciones por el origen social del estudiantado, a tal grado que el visitador de la Real Universidad, Juan de Palafox y Mendoza, decidió incorporar en las nuevas constituciones universitarias una especialmente dedicada a regular el origen y la calidad social de los alumnos y graduados. Se trata de la 246, la cual reflejó el temor de una comunidad reconocida como española, de ver entre sus filas a jóvenes provenientes de otras calidades y estamentos. La referida constitución expresaba que:

Ordenamos que cualquiera que hubiere sido penitenciado por el santo oficio, o sus padres o abuelos, o tuviere alguna nota de infamia, no sea admitido a grado alguno de esta universidad, ni tampoco los negros ni mulatos, ni los que comúnmente se llaman chinos morenos, ni cualquiera género de esclavo o que lo haya sido: porque no sólo no han de ser admitidos a grado, pero ni a la matrícula; y se declara, que los indios, como vasallos de su majestad, pueden y deben ser admitidos a matrícula y grados. ${ }^{14}$

En estas líneas se recogen las inquietudes sociales de los dirigentes de la Universidad de aquellos años. En primer lugar, la prohibición a los penitenciados por la Inquisición o sus descendientes, reflejo innegable de la década de 1640, famosa por los autos de fe de la ciudad de México. ${ }^{15} \mathrm{La}$ frase de la constitución: "[...] o tuviere alguna nota de infamia [...]" siempre se prestó a diferentes interpretaciones que se usaron para atacar a enemigos o detener estudiantes

14 Estatutos y constituciones reales.

15 Alberro, Inquisición y sociedad, pp. 533-585. 
sospechosos de sus orígenes. En el siglo xviII hubo muchos casos de estudiantes de padres desconocidos, hijos naturales, o bien, adoptados en otras familias, que tuvieron que enfrentar esa frase de la constitución $246 .{ }^{16}$

La tercera prohibición de la constitución hace alusión a los negros, los mulatos y los chinos morenos, así como a los esclavos. Esta parte de la ley fue aplicada sin miramientos en el siglo XviII; es decir, si un estudiante era catalogado como negro o mulato, automáticamente era expulsado de la Universidad. Al final se menciona la aceptación de los indios, recordando la cédula fundacional.

Pero si esta constitución respondió en la década de 1640 a las preocupaciones de entonces, en los años posteriores fue rebasada por una realidad social cambiante que ningún legislador podía prever, dando pie a interpretaciones sobre cuál debía ser la calidad social de los estudiantes, en especial cuando éstos presentaban situaciones no consideradas, como fue el caso de los castizos, los mestizos, quienes presentaban defectos de nacimiento, eran hijos de padres desconocidos, expuestos o hijos naturales, eran asiáticos o había indios queriendo graduarse.

La presencia de estudiantes no españoles parece acentuarse en las escuelas de la Universidad en la segunda mitad del siglo xviI, sobre todo en las facultades de Artes y de Medicina. En 1674, el doctor Juan de Brizuela, catedrático de Cirugía y Anatomía, expulsó de su clase a un estudiante de origen filipino, Manuel de Santa Fe, por considerarlo chino moreno. ${ }^{17}$ Cabe mencionar que un año antes, en 1673 , la Real

16 Aguirre Salvador, “Algunas problemáticas”, pp. 135-158.

$17 \mathrm{Al}$ parecer los chinos morenos eran esclavos traídos de Manila, vía la 
Audiencia de México había decretado la liberación de todos los esclavos chichimecos y chinos, ${ }^{18}$ con lo cual probablemente surgió en la capital desconfianza para distinguir a un asiático libre de uno recién liberado. Igualmente, el rechazo del catedrático pudo deberse a que normalmente los asiáticos de la capital desempeñaban oficios domésticos, de barberos o en obrajes textiles. ${ }^{19} \mathrm{El}$ inculpado solicitó entonces al rector, García de León Castillo, que no se le impidiera cursar pues no era de los que "[...] comúnmente se llaman chinos morenos ni he sido ni lo han sido mis padres, esclavos, pues antes son indios japonés $[\ldots]$ vasallos de su majestad [...]". ${ }^{20}$

Desde el siglo xvi, Felipe II había reconocido a sus nuevos vasallos de Filipinas como indios también. ${ }^{21} \mathrm{El}$ rector estuvo de acuerdo, pues la constitución 246 no especificaba el origen geográfico de los indios y ordenó al secretario de la Universidad, en consecuencia, recibir información a Manuel de Santa Fe sobre su calidad social. El secretario certificó que el alumno ya se había hecho acreedor al

Nao de China, que no eran filipinos, sino de otras regiones, posiblemente bajo dominio de Portugal, y, por tanto, no eran vasallos libres de la corona española. Tampoco puede descartarse que fueran esclavos asiáticos mahometanos. Véanse al respecto los artículos de: Oropeza Keresey, "La esclavitud asiática”, pp. 5-57; y CARrillo, “Asia llega”, pp. 81-98.

18 Oropeza Keresey, "La esclavitud asiática”, pp. 46-47.

${ }^{19}$ Carrillo, “Asia llega”, p. 84.

20 AGN, Universidad, 69, exp. 2, f. 1: “Autos hechos sobre la pretensión de matricularse en la facultad de medicina el bachiller Manuel de Santa Fe, entre partes y de la otra el doctor Juan de Brizuela, catedrático de Cirugía y Anatomía en esta Real Universidad. Juez: el señor doctor don García de León Castillo, rector".

${ }^{21}$ Recopilación de leyes, tomo segundo, libro VI, título VII, ley XV: "Que los indios principales de Filipinas sean bien tratados y se les encargue el gobierno que solían tener en los otros". 
grado de bachiller en Filosofía pocos días antes. Luego de tales informaciones, el rector, quien además era juez ordinario del Santo Oficio: “[...] declaraba y declaró [...] no ser de los comprendidos en la constitución doscientas cuarenta y seis y mandaba y mandó se le admita la matrícula para cursar la facultad de Medicina y ningún catedrático de los de dicha facultad se lo impida[...]".22 Cabe destacar la decisión del rector de hacer una interpretación muy acotada de la constitución; es decir, sólo aplicar la constitución a quienes expresamente estuvieran señalados y no más: negros, mulatos o chinos morenos.

En 1691 otro estudiante filipino, Nicolás de la Peña, quizá teniendo en cuenta el caso de Santa Fe, ofreció voluntariamente demostrar no ser chino moreno, sino antes bien, hijo de indios principales, el equivalente filipino de los caciques novohispanos. ${ }^{23} \mathrm{El}$ rector, por entonces Agustín de Cabañas, aceptó el interrogatorio propuesto por el asiático ${ }^{24}$

${ }^{22}$ AGN, Universidad, 69, exp. 2, fs. 2v-3.

23 Álvarez, "Los señores del Barangay".

${ }^{24}$ AGN, Universidad, 42, f. 603. "Información de Nicolás de la Peña y licencias para cursar en esta universidad. 1691", f. 603v.: "Interrogatorio por donde han de ser examinados los testigos de parte para la información que ha de dar Nicolás de la Peña por las preguntas siguientes: $1^{\circ}$. Primeramente si conocen a Nicolás de la Peña natural del pueblo de Alvucai [sic] provincia de la Pampanga en las islas Filipinas. 2o. Si los testigos les tocan las generales, si son de la edad que el derecho disponen, digan 3o. Item. Si saben que el dicho Nicolás de la Peña es indio natural de la dicha provincia de Panpangos, si son vasallos libres de S. M. O si es de los que comúnmente llaman chinos morenos conforme a la constitución doscientas cuarenta y seis de los estatutos de esta real universidad, digan 4o. Item. Si conforme a dicha constitución el dicho Nicolás de la Peña o sus padres o abuelos han sido o son penitenciados por el Santo Oficio de la Inquisición o si han tenido nota de infamia porque teniéndola o siendo 
y decidió también, a diferencia de su antecesor, ventilar esta vez el asunto con el abogado de la Universidad, el catedrático de Instituta José de Miranda Villayzan. El parecer de este último es por demás interesante:

En conformidad de este proveimiento y remisión que se sirve de hacer el señor rector, he reconocido la pretensión de Nicolás de la Peña y probanza con que la instruye y hallo que, por ella, consta ser de los indios filipenses, natural y originario de la provincia de la Pampanga y de padres naturales también de ella, por cuya razón es vasallo libre y generalmente lo son los de las islas Filipinas por varias leyes que así lo tienen dispuesto $[\ldots] .^{25}$

Con este parecer, Agustín de Cabañas ya no tuvo reparos en admitir al estudiante filipino en la universidad. No sabemos aún si en los tiempos posteriores siguieron arribando filipinos, pues las fuentes de la institución no dicen mucho al respecto.

En 1689, ante el aumento de estudiantes no españoles, hubo nuevos intentos por restringir su ingreso a las escuelas, a raíz de los cambios de requisitos para la matriculación de estudiantes. El rector José Amurrio del Campo ordenó que "[...] todos los estudiantes que pretendieren matricularse en cualquiera facultad presenten fe de bautismo en

comprendido en las personas prohibidas por dicha constitución no pueden ser admitidos a grado de bachiller ni a la matrícula de los estudiantes de esta real universidad. 5o. Si saben o han oído decir que el dicho Nicolás de la Peña ha estudiado gramática y si la sabe para poder ser admitido a matrícula para cursar conforme a estatutos un curso en Retórica antes de entrar a oír facultad mayor [...]".

${ }^{25}$ AGN, Universidad, 42, f. 606. 
debida forma $[\ldots]$ ". ${ }^{26} \mathrm{El}$ secretario pasó, cátedra por cátedra, a notificar lo anterior e hizo constar las fes de bautismo presentadas por los cursantes del momento, todas señalando matrimonios legítimos y el origen español de los siguientes estudiantes: Antonio Sedillo, de Artes; Miguel Caballero, Pedro José Arias, Alfonso Arias, Juan Antonio de Burgos Castañeda, Tomás Téllez, Nicolás Zamudio, Jacinto González de Laris, Diego de los Reyes, Matías González de Maya, Salvador Díaz, hijo de la iglesia, asentado en libro de españoles, Baltasar González Lazcano, Juan carro de la Vega y Antonio Carro, hermanos, Eligio José de Vergara, Pedro de Arteaga, artista; Matías de Ayala, artista; Nicolás de Porras, artista; Luis Clemente Astorga, artista; Alejo López, Gaspar de León, Nicolás Fernández.

En 1696 el virrey interino y obispo de Michoacán, Juan Antonio de Ortega Montañés, preocupado por las posibles ligas de los estudiantes con el tumulto de la ciudad de México de 1692, intentó expulsar de la Universidad a aquellos no considerados españoles, sobrepasando lo estipulado por las propias normas estatutarias de la Universidad. ${ }^{27}$ Esa medida radical, sin embargo, decayó una vez que el prelado dejó el cargo de virrey. Los dirigentes de la Universidad fueron tolerantes ante la demanda de estudios de una población cada vez más heterogénea. Además, nuevas cédulas reales de fines del XVII habrían influido en una mayor apertura a los indios y los mestizos, en los colegios y en el sacerdocio. ${ }^{28}$

\footnotetext{
${ }^{26}$ AGN, Universidad, 42, fs. 422-433. Año de 1689.

${ }^{27}$ AGN, Universidad, 43, f. 229. "Auto del señor rector para que se guarde y cumpla el edicto para la observancia de las constituciones sobre los trajes de los cursantes y lo demás que contiene el dicho edicto."

${ }^{28}$ Menegus y Aguirre, Los indios, el sacerdocio y la Universidad, cap. 2.
} 
Por esa misma época, la tasa de nacimientos ilegítimos en la ciudad de México alcanzaba a por lo menos una tercera parte de españoles, mestizos y castas. ${ }^{29}$ Es indudable la relación que guardaba este proceso con lo que sucedía en las instituciones a quienes se les demandaban estudios, como la universidad. En ese mismo sentido habría que insertar la sensibilidad política de la monarquía al cambio social en Indias, y en consecuencia, el impulso que dio al ascenso de indios nobles y mestizos, aunque no de manera indiscriminada, puesto que siempre distinguió a los caciques de los maceguales, y a los mestizos legítimos, cercanos al ideal español, de los nacidos fuera de matrimonio.

El último grupo social no español en hacer su aparición claramente en la universidad del siglo xvir fue el de los indios. Desde la década de 1530 se examinó la pertinencia de asimilarlos a la clerecía. Los franciscanos defendían que como vasallos libres y antiguos señores de la tierra, debían gozar de todos los privilegios que los españoles. La postura opuesta, defendida por encomenderos y colonizadores españoles, consideraba que los naturales, como parte del pueblo conquistado, no debían tener tales prerrogativas. ${ }^{30}$

Cuando se fundó la Universidad en 1551, aunque se les permitió el acceso formal, en la práctica los grandes trastornos que ya estaba experimentando la población indígena y su nobleza obstaculizaron seriamente su acceso a los estudios mayores. Aunque se fundaron poco después algunos colegios para indios por los jesuitas, los estudios ahí

${ }^{29}$ Gonzalbo, Familia y orden colonial, p. 178.

30 Menegus, “Dos proyectos”, pp. 83-89. 
impartidos fueron de primeras letras básicamente. ${ }^{31}$ Hasta mediados del siglo xvir el asunto pareció finiquitado: con una población indígena en sus peores momentos demográficos y su nobleza empobrecida, una educación universitaria para ella parecía un asunto olvidado. A fines del siglo xvII, nuevas políticas reales y condiciones de la población indígena ocasionaron un cambio de expectativas. En primer lugar, la reconstitución de las comunidades indígenas y el inicio de su recuperación demográfica; en segundo, una política favorable de Carlos II en favor de la nobleza indígena, cuya esencia consistió en darle acceso a los mismos cargos que a los españoles; y en tercero, la disposición de los caciques a buscar un destino eclesiástico para su descendencia, luego de casi dos siglos de asimilación a la cultura hispánica. ${ }^{32}$

El 12 de marzo de 1697 la corona decidió favorecer a la nobleza indígena con una cédula, que sería confirmada en 1725 y en $1766,{ }^{33}$ según la cual los caciques debían ser considerados como del estado general de los españoles y, por tanto, candidatos a ocupar los mismos cargos civiles, políticos y eclesiásticos.

En la Universidad, los rectores siguieron apegándose a la constitución 246 que permitía a los indios en general el acceso a cursos y a grados. No obstante, los estudiantes indios que comenzaron a tocar las puertas universitarias decidieron

${ }^{31}$ Gonzalbo, Historia de la educación... El mundo indígena, pp. 153-173.

32 Para un mayor análisis de estos procesos véase Menegus y Aguirre, Los indios, el sacerdocio, caps. I y II.

33 AGN, Universidad, 269, ff. 762v.-763: "Año de 1770. Autos hechos para el grado de licenciado en Sagrados Cánones del bachiller don José Antonio Ximenes Baptista Frías, clérigo presbítero, domiciliario de este arzobispado y abogado de esta Real Audiencia”. 
manifestar su calidad no macegual y se declararon hijos de caciques o principales, a tono con la cédula de 1697, a pesar de que no había alguna declaración explícita de la corporación universitaria en que ordenara aceptar sólo a hijos de caciques. Por supuesto que otro factor de peso pudo ser que los caciques sí contaban con los recursos para educar a sus hijos, a diferencia de la pobreza de los indios tributarios, además de que el tributar pudo considerarse por entonces una nota de infamia. ${ }^{34}$ Con todo, las autoridades siguieron mostrando preferencia por la nobleza, como lo prueban las constituciones del nuevo seminario conciliar de México, que consideraba dar becas sólo a indios nobles. ${ }^{35}$

Lo cierto es que desde fines del siglo xvir la presencia indígena en la Universidad dejó de ser algo excepcional. A medida que trascurrieron los años y sin dejar de ser nunca un sector minoritario, el número de estudiantes y graduados indios se acrecentó de manera importante. La relación indios universidad se dio por dos vías: los cursos en las escuelas universitarias y los grados de bachiller por suficiencia. Los indios que asistían a las aulas de la Universidad podían ser también colegiales en alguna institución de la capital, o bien, ser únicamente cursantes de la primera. ${ }^{36}$

34 Cabe recordar aquí que las becas de indios que se abrieron en el seminario conciliar de México se destinaron sólo a hijos de caciques.

35 Aguirre Salvador, Un clero en transición, p. 32.

36 Gonzalbo, Historia... La educación de los criollos, p. 168. Por antiguos acuerdos, los estudiantes de los colegios de México debían cursar también en la Universidad si aspiraban algún día a graduarse, lo cual implicaba en los hechos que todos debían estar matriculados o inscritos por el secretario universitario. 
Es difícil precisar el número de indios que cursaron en la Universidad. En los libros de matrículas de estudiantes no se asentó la calidad social de los estudiantes, salvo algunas excepciones que nos pueden llevar fácilmente a la idea de su excepcionalidad. Sin embargo, otras fuentes prueban plenamente su presencia en las aulas: entre 1692 y 1724 fueron ya $11 .{ }^{37}$ Este pequeño conjunto era en realidad sólo una fracción de un conjunto mayor que es más difícil identificar. Además, tomando en cuenta la densidad de población indígena y de linajes nobles en el centro y en el sur de la Nueva España, no es creíble un número tan corto. En otra fuente se confirmó pronto tal hipótesis: los registros de grado de bachiller de la misma universidad. ${ }^{38}$ Los indios que alcanzaron el grado de bachiller en Artes fueron al menos 134 en el periodo de 1711 a 1822, la mayoría de la segunda mitad del siglo XviII y las primeras décadas del XIX. ${ }^{39} \mathrm{Y}$ decimos al menos porque los hijos de caciques del seminario conciliar de México que alcanzaron un grado no aparecen así registrados en la Universidad. Calcular el número de indios, cursantes o procedentes de colegios de otras provincias novohispanas, que fueron graduados por la Universidad, es ciertamente una tarea difícil por lo inexacto y la escasez de fuentes, por lo que la cantidad antes mencionada es un mínimo.

Aunque menos visibles en los registros escolares, los mestizos y los mulatos también estuvieron presentes en la Universidad. Desde el siglo xviI se tiene noticia de mulatos en

37 AGN, Universidad, $42-46$ y 70-71.

38 Para este tipo de fuentes y sus posibilidades puede verse el trabajo de Aguirre Salvador, “Los registros de grado”, pp. 145-183.

39 AGN, Universidad, 167-170 y 293. 
Medicina, como ya se mencionó antes. Para el siglo xviII se acepta mucho menos su existencia, justo cuando la sociedad novohispana alcanzó su máximo nivel de mestizaje. Sin duda, la preocupación de los sectores criollos por defender su distinción y privilegios, y que se autodefinían como la cúspide de la sociedad, incluyendo a los doctores universitarios, era proporcional a esa mayor diversidad social que se asomaba claramente a las aulas universitarias. A ello hay que agregar el eco provocado por las críticas en Europa a la inferioridad de los españoles americanos. ${ }^{40}$ Pilar Gonzalbo ha sugerido que muchos hijos de castas fueron favorecidos por los curas para ascender en la jerarquía social al momento de bautizarlos. ${ }^{41}$ De no ser así, cualquier estudiante tachado de mulato o descendiente de negros recibía todo el peso de la constitución 246 y era rechazado de la universidad. Por ello es que en los registros universitarios aparecen en realidad muy pocos casos.

¿Hasta qué punto inquietaba a la Universidad dar el máximo grado a un mulato? Puede darnos una idea el ejemplo del bachiller Agustín Rodríguez Medrano Vázquez, presbítero y abogado, quien tuvo que pasar por toda una investigación de sus antecedentes familiares y sociales. ${ }^{42}$ Todo comenzó con una denuncia anónima que llegó a manos del rector, según la cual la madre del bachiller era

\footnotetext{
40 Alberro y Gonzalbo, La sociedad novohispana, pp. 149-150.

${ }^{41}$ Gonzalbo, Familia y orden colonial, p. 180: “Se diría que los párrocos miraban con cierta tolerancia a los recién nacidos sobre quienes derramaban las aguas del bautismo y estaban dispuestos a clasificarlos en la categoría inmediatamente más favorable".

${ }_{42}$ Expediente del bachiller Agustín Rodríguez Medrano, México, 1772. AGN, Universidad, 270, ff. 147-235.
} 
mulata. Igualmente, se rumoraba que, al casar su padre con una mujer de calidad inferior, no había podido lograr ascensos, por lo que había enloquecido. Además, se afirmó que el Colegio de Abogados había rechazado a Rodríguez Medrano y que la Inquisición le había negado también el cargo de notario. Tales ideas ocasionaron que su proceso de graduación de doctor se suspendiera.

Si bien la Universidad había dado ya grados a españoles expuestos e indios, aceptar a un hijo de mulata como doctor significaba una clara transgresión a la constitución 246. No obstante, el catedrático jurista Ambrosio Llanos de Valdés declaró que no debía negársele el grado a Rodríguez Medrano por simples rumores sobre la calidad de la madre, pues en realidad no existían pruebas contundentes. El catedrático no rechazaba propiamente la constitución 246 sino la calificación social del bachiller. Otros dos catedráticos juristas, Agustín Bechi y José Pereda Chávez, expresaron que el parecer de Llanos no era decisivo y que hacía falta una averiguación secreta y amplia. El acusado, enterado de la suspensión de su grado, solicitó copia de los autos para alegar en su derecho y expresando que sospechaba de un enemigo que quería manchar su calidad.

Luego de las averiguaciones, efectuadas por el secretario de la Universidad, se comprobó que Rodríguez Medrano nunca había sido rechazado por el Colegio de Abogados ni por el Santo Oficio. El secretario averiguó que en realidad el pretendiente solo había sido amanuense y notario interino en la Inquisición, por encargo y favor, pero que nunca pretendió la titularidad y por lo tanto no tuvo por qué probar su calidad. En vista de esto, los catedráticos Bechi y Pereda ya sólo pidieron nueva información al 
doctor, con testigos de calidad y que probara la limpieza de su abuelo materno, una vez que ya hubiese presentado las constancias de bautizo de su madre y de su abuela. Aun así, el secretario interrogó todavía a 21 nuevos testigos sobre la calidad de la familia y de Rodríguez Medrano. Es indudable que a la corporación universitaria le preocupaba sobremanera aclarar este tipo de casos para salvaguardar su prestigio ante la sociedad.

Pero el cambio social se reflejó también en los estudiantes considerados españoles; me refiero a los que eran señalados como hijos ilegítimos, naturales o expuestos. Ante el aumento de casos en el transcurrir del siglo XviII, la corporación universitaria hubo de aceptar otra vez las nuevas realidades sociales, ya no de los indios o los mestizos, sino del sector con el que más se identificaba, aun si para ello debía hacer una interpretación más amplia de sus estatutos.

Desde fines del siglo XviI comenzaron a presentarse casos de españoles con algún defecto de nacimiento. ${ }^{43} \mathrm{Si}$ el estudiante era capaz de demostrar con su fe de bautizo y con testigos juramentados que, a pesar de su nacimiento, era español, la Universidad lo aceptaba. Para la segunda mitad del siglo XviII los casos de ilegitimidad o de expuestos registrados aumentaron considerablemente, tal y como sucedió con la presencia indígena. Incluso en los grados mayores podemos encontrar a hijos naturales o expuestos. En el sector de los bachilleres se presentó el mayor número de casos al respecto:

${ }_{43}$ AGN, Universidad, 43, f. 497. Un estudiante español se declara hijo de la Iglesia. 
BACHILLERES CON DEFECTO DE NACIMIENTO ENTRE 1749 Y 1813

\begin{tabular}{lc}
\hline Defecto & Casos \\
\hline Expuestos & 117 \\
De padres desconocidos & 43 \\
Hijos naturales & 14 \\
Total & 174 \\
\hline
\end{tabular}

FuENTE: AGN, Universidad, 167-170.

Esta mayor apertura de la Universidad cuestionaba ya los viejos parámetros sociales bajo los cuales había nacido y se había consolidado en el siglo xvir, como expresó un catedrático del periodo colonial tardío al criticar lo anticuado de la constitución 246, en una época en que, expresó, ni siquiera en las universidades más célebres de España tenían algo parecido. ${ }^{44}$

Algo característico de los bachilleres con defecto de nacimiento es que fueron adoptados y criados en familias reconocidas como españolas. Para ellos fue esencial demostrar que sus padres adoptivos eran españoles. Su principal argumento fue que, de no haber sido españoles, no hubieran sido aceptados en una familia "decente". ${ }^{45}$

44 "Y aunque la constitución 246 de esta Real Universidad, que es la que dispone sobre las cualidades que deben concurrir en los sujetos que se han de admitir a matrícula y grados, exija una tan gran pureza de sangre cual no se exige ni aun en la primera de la monarquía (Salamanca) ni en ninguna otra, como nota el Señor Adame en la glosa 2224.” AGN, Universidad, 386, fs. 210-253. Expediente del bachiller Juan Bautista Picazo Montoya. México, 1796.

${ }^{45}$ El único caso localizado de un graduado que, por ser expuesto, se le hayan negado los grados, fue el de Juan Antonio Jacinto del Villar, en 1710, hijo natural de Juan Manuel Rodríguez, tratante y dueño de un almacén de labores orfebres. Jacinto fue expuesto en la casa de Juan de 
El fenómeno social se presentó también en los doctores, en donde hubo hasta 35 casos de expuestos, hijos naturales o de padres desconocidos. ${ }^{46}$ Los juristas de la Universidad impulsaron la apertura de los grados mayores para estos casos. El doctor Beye expresó que, aunque la común opinión fuera que los expuestos deberían quedar excluidos de empleos, comunidades y colegios, no obstante existía:

[...] una ley que lo decide y es la real cédula fecha en Aranjuez a 19 de febrero de 94, hoy publicada por bando en esta ciudad a 30 de julio del mismo año. Por ella manda el rey que los expuestos, en cualquier lugar o casa, sean tenidos por legítimos, y los legitima su majestad para todos los efectos civiles, generalmente, y sin excepción, declarando que la cualidad de expósito no sirve asimismo, que todos los expósitos mientras no consten sus padres verdaderos, queden en la clase de hombres buenos del estado llano: y por último que sean admitidos en los colegios, o convictores a menos que sus estatutos, o fundaciones prevengan que sean legítimos y de legítimo matrimonio nacidos: de consiguiente sólo en estas circunstancias podrán excluirse[...] Por tanto siendo como es constante por la información testimoniada que ha presentado dicho bachiller Picazo, que es expuesto debe ser tenido por hombre bueno del estado llano, sin nota alguna de infamia [...] y vuestra señoría, si es servido, puede admitirlo a los grados mayores [...] Febrero 10 de 1796 [...].

Como podemos apreciar, el rey dejó la última decisión a las mismas corporaciones con estatuto o alguna norma de exclusión, como la Universidad. El jurista no consideraba ya el

Saga Villar. AGN, Universidad, 264, fs. 311-334. Expediente del bachiller Juan Antonio Jacinto del Villar, México, 1710.

46 Aguirre Salvador, El mérito y la estrategia, pp. 103-105. 
ser expuesto como un signo de infamia, opinión compartida ya normalmente por el resto de la corporación universitaria. Ahora bien, si en las aulas universitarias llegaron a compartir los mismos espacios estudiantes de varios orígenes sociales, ello no significó que hicieran similares trayectorias públicas.

\section{DIFERENTES DESTINOS}

El origen familiar y el medio social al que pertenecían los estudiantes fue también un factor de peso, tanto en sus vidas como en sus carreras públicas. Aunque jóvenes de diferentes estamentos y calidades sociales pudieran compartir los espacios universitarios y académicos, ello no significaba que también lo hicieran en la sociedad y el medio de su profesión. La apertura de los estudios mayores no garantizaba a grupos de bajo rango social un encumbramiento profesional, pues para lograrlo existían factores que rebasaban el ámbito universitario y académico. Esta realidad puede verse bien dentro del clero secular, uno de los destinos más buscados por los estudiantes universitarios.

\section{De la Universidad al alto clero del arzobispado}

El clero secular del arzobispado de México estaba constituido por individuos que también provenían de varias capas sociales: criollos de diversos niveles de riqueza y educación, mestizos integrados a alguna de las repúblicas de indios o de españoles, e integrantes de la nobleza indígena a partir del siglo xviII. ${ }^{47}$ Esta clerecía reflejaba, como

47 Ganster, "Miembros de los cabildos". Menegus y Aguirre, Los indios, el sacerdocio y la Universidad. 
los universitarios, la heterogeneidad de la sociedad novohispana.

En el mundo de los empleos eclesiásticos existían diferencias notables. Había un primer sector de clérigos con grados de bachiller en Artes, en Teología o en alguno de los derechos, sin recursos o interés por hacer una carrera de altos vuelos en la capital, y cuya vida transcurrió en los desolados curatos rurales de la arquidiócesis. ${ }^{48}$ En cuanto al bajo clero urbano, se caracterizaba por desempeñar cargos inferiores durante toda su vida. ${ }^{49}$ Un tercer sector, más afortunado, era el de los clérigos dedicados a servir capellanías de misas, pues de los capitales impuestos obtenían rentas que aseguraban un mínimo de subsistencia. ${ }^{50}$

El sector dominante del clero secular, miembros del cabildo catedralicio, funcionarios de la curia arzobispal, los curas de la capital o catedráticos universitarios, era una minoría caracterizada por sus altos grados académicos, por tener recursos económicos suficientes, a veces cuantiosos, por provenir de familias distinguidas y bien relacionadas, por desempeñar una serie de actividades o líneas de profesión y por estar integrados a corporaciones o grupos de poder desde donde se encumbraban. ${ }^{51}$

Difícilmente un clérigo podía aspirar a tener éxito en su carrera de manera aislada o individual. En el Antiguo

${ }_{48}$ AGN, Bienes Nacionales, 236, exp. 24 Provisión de curatos del arzobispado de México. Relaciones de méritos de opositores.

${ }^{49}$ AGN, Bienes Nacionales, leg. 801, exp. 1 o leg. 320, exp. 12, por ejemplo. 50 AGI, México, 2547. Febrero de 1764. Informe reservado de la clerecía del arzobispado de México, por Manuel José Rubio y Salinas.

${ }^{51}$ Aguirre Salvador, El mérito y la estrategia, pp. 279-392. 
Régimen los grupos o colectivos eran más importantes. ${ }^{52}$ Así, las carreras eclesiásticas no pueden entenderse del todo sin comprender los vínculos y las relaciones de los clérigos. ${ }^{53}$ Alrededor del cabildo eclesiástico, de los curatos de la capital, de los tribunales eclesiásticos y de los catedráticos universitarios se conformaban grupos clientelares importantes que pesaban en el destino de sus integrantes. ${ }^{54}$ Lo que más caracterizó al clero en ascenso de México, y de lo que dependía su fama y distinción, fue su capacidad de construir relaciones con la jerarquía del arzobispado, cabildo y arzobispo fundamentalmente, aunque también con otras instancias de gobierno y de poder, como el virrey, la Audiencia, el Ayuntamiento o el Consulado de Comerciantes. Los méritos que iban logrando los clérigos eran consecuencia de los vínculos formados en los exámenes para ganar las órdenes sacras, en los cursos, en las oposiciones a cátedras, curatos o canonjías, en la participación o asistencia a los actos religiosos y sociales de la capital, vínculos que, bien cuidados, podían convertirse en lazos de amistad o clientelares. ${ }^{55}$

52 Ganster, "La familia Gómez de Cervantes”. Chacón Jiménez, “Estructuración social”, pp. 355-362.

53 Aguirre Salvador, El mérito y la estrategia, pp. 279-392.

${ }^{54}$ La relación entre los cargos eclesiásticos y el ejercicio del poder en Nueva España no ha sido un tema recurrente en la historiografía, salvo algunos análisis que han primado ante todo la relación Iglesia-monarquía. Aunque se han hecho estudios de tipo prosopográfico sobre algunos sectores clericales, que nos indican ciertos patrones externos de ese universo, muy valiosos por otro lado, aún faltan estudios profundos sobre la conformación de grupos internos y su participación en los juegos de poder y las prácticas políticas. Véase por ejemplo Ganster, "Miembros de los cabildos eclesiásticos".

${ }^{55}$ A medida que se avanza en el conocimiento de la clerecía de la época se hacen más nítidas las diferencias en cuanto al nivel de relaciones entre 
En el claustro universitario, máximo órgano de gobierno conformado por doctores, predominaba el alto clero del arzobispado y sus clientelas. Hacia el último cuarto del siglo xvir la Real Universidad de México tomó el camino definitivo de la clericalización; esto es, el clero secular, vía sus miembros con grado doctoral, terminó por hacerse del control de las cátedras principales, el rectorado y los órganos de gobierno. Aunque estudiantes y doctores laicos, como los médicos y uno que otro legista, siguieron teniendo presencia, sin embargo tuvieron un lugar secundario. ${ }^{56}$ De ahí que desde la Universidad se pudieron construir sólidas carreras eclesiásticas para quienes contaban además con buenas relaciones al exterior. El siguiente caso ejemplifica bien ese modelo de trayectorias.

Desde los cursos universitarios los estudiantes entraban en contacto con jerarcas del alto clero del arzobispado, al fungir éstos como catedráticos o examinadores de grado; los alumnos más destacados o mejor relacionados hallaban patrocinadores que, eventualmente, se convertían en francos protectores. Fue en este contexto institucional donde se desarrolló la trayectoria de José de Torres Vergara, hijo de

el clero rural y el enclavado en la ciudad de México. Retomando la propuesta de FAUST, "Las redes sociales”, pp. 1-14, sobre saber diferenciar la "densidad" de relaciones de cada actor histórico, un ayudante de cura o un coadjutor alejado de la ciudad, difícilmente tenían una presencia en las instituciones y dependencias eclesiásticas y sus nombres están ausentes de los memoriales de la Universidad o de los arzobispos; cuando mucho aparecen los curas propietarios o algunos clérigos avecindados en la capital. ${ }^{56}$ Los doctores médicos, en especial, fueron sensibles a tal estado de cosas, e intentaron, de forma colegiada, ganar más espacio en una corporación dominada por teólogos y canonistas que eran o aspiraban a ser del alto clero. 
un regidor de la ciudad de México, entre 1678 y 1700, quien nos relata en una relación de méritos que, siendo estudiante de Filosofía, realizó un acto académico dedicado al cabildo eclesiástico de México, el cual estuvo presidido por el arcediano de la catedral, el doctor Juan de la Peña Butrón. Aunque no es seguro que ese dignatario haya favorecido después a nuestro personaje, fue un hecho que Torres se hizo notar desde entonces por los capitulares.

Torres Vergara fue parte de una generación que estudió derecho entre 1678 y 1682 aproximadamente y estuvo compuesta por alrededor de ocho estudiantes. ${ }^{57}$ De ellos, dos se convirtieron en amigos de Torres y juntos compartieron una década más de actividades en la Universidad: Guillermo Dorlan y Pedro de Recabarren. ${ }^{58}$ De ese grupo fue Torres Vergara quien llegó más lejos y cuya carrera representa los patrones de ascenso del clero vigentes por entones. Un catedrático y miembro del alto clero, a quien Torres apoyaría después en sus ascensos, fue quien le otorgó el grado de bachiller en Cánones en 1679: el doctor Diego de la Sierra, ${ }^{59}$ personaje que lo protegió en los inicios de su carrera. De la

57 AGN, Universidad, 41, f. 512. Se trata de Pedro de Valdés, Antonio de Jáuregui Bárcena, Guillermo Dorlan, Pedro Recabarren, Salvador Guerra, Francisco González Elías, Antonio de Torres y José Torres Vergara.

${ }^{58}$ Dorlan, junto con Torres, participó en varias oposiciones a cátedras. La cercanía se refleja en el hecho de que Dorlan estuvo presente en momentos tan importantes como la graduación de bachiller de Torres, y éste a su vez asistió a las lecciones de oposición del primero. Otro condiscípulo, el br. Pedro de Valdés, tuvo mucha cercanía en la época estudiantil pero al parecer desapareció después de la Universidad. AGN, Universidad, 100. Provisión de la cátedra de Instituta.

59 AGN, Universidad, 263, f. 453. Grado de doctor en Cánones de José de Torres y Vergara. Diego de la Sierra llegó a convertirse en el "brazo derecho" del arzobispo Aguiar y Seijas (ha. 1680-1698), primero como 
Sierra era además cabeza de un grupo clerical al que se integró nuestro personaje como cliente y protegido en los años posteriores.

En 1683 Torres Vergara obtuvo el grado de doctor, privilegio que sólo una minoría de letrados alcanzó a lo largo de la época colonial. ${ }^{60}$ Por ello era importante escoger a un buen padrino de grado que a futuro pudiera convertirse en un protector, o, mucho mejor, quien introdujera al ahijado a un grupo o red clerical. Tal parece haber sido la intención de Torres al conseguir como su padrino y mecenas de grado al clérigo y doctor Juan de Narváez, rector de la universidad, quien por entonces se hallaba en franca carrera para ingresar al cabildo catedralicio de México ${ }^{61}$ La relación maestroalumno se transformaba en el lazo prebendado-clérigo fuera de la universidad. Torres no se equivocó pues hacia $1686 \mathrm{su}$ padrino obtuvo finalmente una prebenda en el cabildo mexicano $^{62}$ y él una posibilidad de recomendación para futuros ascensos. Es sabido que los miembros de los cabildos acostumbraban ayudar a sus ahijados y protegidos para obtener buenos curatos y otros beneficios eclesiásticos. ${ }^{63}$

La cátedra universitaria se había convertido, para los clérigos, en una especie de prebenda eclesiástica dada la gran

provisor-vicario general y después como gobernador de la jurisdicción, hasta su deceso, ocurrido en 1691.

60 Aguirre Salvador, El mérito y la estrategia, cap. VI.

61 AGN Universidad, 263, fs. 453-468. Ser padrino de un nuevo doctor daba buena fama, aspecto fundamental en la sociedad de la época.

62 GonzÁlez, "Mecenazgo y literatura”.

63 AGI, México, 806. Años de 1738-1742. Cartas del arzobispo-virrey Juan Antonio de Vizarrón, sobre la provisión de curatos de Puebla en ahijados del cabildo catedralicio. 
influencia del alto clero en su provisión. ${ }^{64}$ Torres inició las oposiciones por las cátedras en $1683,{ }^{65}$ estrategia común de los clérigos juristas de la capital. En 1688, a los 27 años de edad, Torres obtuvo su primera designación como sustituto del catedrático de Vísperas de Leyes, integrándose al cuerpo de universitarios candidatos a las prebendas, dada la alta incidencia cátedra-prebenda. ${ }^{66} \mathrm{El}$ hecho de que Torres contara con el voto del arzobispo en esta oposición le indicaba ya cierto reconocimiento del alto clero, no solamente para ganar cátedras sino para futuras prebendas o cargos eclesiásticos de la curia. ${ }^{67}$ Así, en la década de 1690 , nuestro

\footnotetext{
${ }^{64}$ Aguirre Salvador, Por el camino, pp. 31-36.

${ }^{65}$ Torres y Vergara inició su ascenso en la Universidad en 1684 como sustituto del catedrático de Vísperas de Leyes en los meses de junio a septiembre. Las constituciones de la Universidad permitían a los catedráticos titulares nombrar sustitutos en los últimos meses del ciclo escolar. Ello permitía a los jóvenes graduados comenzar a ejercitarse en la docencia. Por ese mismo año, Torres inició sus oposiciones a cátedras y entre 1684 y 1687 opositó en cinco ocasiones.

${ }^{66}$ AGN, Universidad, 101. Provisión de la cátedra de Vísperas de Leyes en sustitución de 1688. En noviembre de 1688, Torres se presentó a opositar debido a la jubilación del doctor Francisco de Aguilar, quien le había dado en 1682 el grado de bachiller en Leyes. Su fiador fue su propio padre, siendo rector Rodrigo García Flores, a la sazón cura de la capital y cercano al cabildo, personaje que se integraría al grupo familiar de Torres y que incluso llegaría a ser deán. Los jueces de la votación fueron el arzobispo Aguiar y Seixas, los oidores Juan de Arechaga y Francisco Marmolejo, el rector Francisco de Aguilar, el maestrescuela Juan Ignacio de Hoyos Santillana y el decano de la facultad de Leyes, el doctor José Osorio Espinosa. La votación: 4 votos para Torres y 2 para Amurrio. AGN, Universidad, 101. Provisión de la cátedra de Vísperas de Leyes en sustitución de 1688.

${ }^{67}$ En el arzobispado de México los catedráticos de Teología y Cánones conformaban un subgrupo clerical de mucho peso, no sólo por la importancia que la cátedra tenía en la carrera eclesiástica sino por sus estrechas ligas con el alto clero del arzobispado y aun con la corte ibérica.
} 
personaje fue nombrado juez de testamentos, capellanías y obras pías del arzobispado, el cual ya no dejó sino hasta su deceso, 36 años más tarde. ${ }^{68} \mathrm{El}$ acceder a tal cargo confirmó su estatus de protegido del arzobispo. La llegada de Torres Vergara al juzgado de testamentos le dio una amplia presencia y reconocimiento en los círculos clericales y del crédito eclesiástico del arzobispado ${ }^{69}$ lo que se tradujo en un ascenso regular en las cátedras universitarias y la consecución de uno de los principales curatos de la arquidiócesis, por lo menos hasta antes de que falleciera el arzobispo Aguiar y Seijas. ${ }^{70}$ Así, opositó y obtuvo sin dificultad en 1698 un curato de catedral.

${ }^{68}$ AGN, Universidad, 101. Relación de méritos del doctor José de Torres y Vergara. Además tuvo el puesto honorífico de subpromotor para la beatificación de Gregorio López. El cargo de juez de testamentos era, junto con el de provisor, el más importante de la curia debido al manejo de los cuantiosos capitales de origen pío. Todo indica que Torres se desempeñó eficazmente y se ganó toda la confianza del arzobispo Aguiar y Seijas. Uno de sus colegas, un prebendado, calificó su talento de "superlativo". ${ }^{69}$ El juzgado de testamentos se había convertido en una fuente de créditos para miembros de varios sectores de la población. Véase Wobeser, El crédito eclesiástico, pp. 69-78.

70 En 1693, ya siendo juez de testamentos, Torres obtuvo su segunda cátedra, la de Instituta. En 1696 renuncia a esta cátedra por haber ganado la propiedad de Vísperas de Cánones. En el mismo año vuelve a opositar por una canonjía doctoral de la catedral metropolitana. Hasta ese momento, Torres había conseguido sus mayores logros en la Universidad, pues cimentaba su carrera como catedrático con miras a obtener una de las primeras cátedras, hacer antigüedad y jubilarse. Según las constituciones universitarias, un catedrático que aspirara a jubilarse debía sumar un mínimo de 20 años de antigüedad. En el caso de los juristas, se les tomaban en cuenta los años de lectura tanto en la facultad de Leyes como en la de Cánones. Aguirre Salvador, Por el camino, pp. 94-101. 
Luego de dos décadas de iniciada la carrera eclesiástica, nuestro personaje finalmente obtuvo una media ración en 1704. ${ }^{71} \mathrm{~A}$ partir de ese momento su ascenso por las prebendas y dignidades fue sistemático: de medio racionero a racionero, a canónigo, a tesorero, a maestrescuela, a chantre y finalmente a arcediano, poco antes de morir en $1727 .{ }^{72}$ Entre 1704 y 1727, Torres Vergara se convirtió en una de las cabezas del arzobispado, pues no sólo gobernó el juzgado de testamentos, sino también encabezó la defensa del claustro de doctores de la Universidad en un largo pleito con el Colegio Mayor de Todos los Santos, se desempeñó como examinador de los aspirantes a ordenarse de sacerdotes y, cuando accedió a la maestrescolía, pudo dar los grados mayores de la Universidad a los futuros dirigentes del arzobispado. Además, en la década de 1720, fue nombrado asesor legal del arzobispo para atender los conflictos ocasionados por la recaudación del subsidio eclesiástico, recién establecido en las Indias. ${ }^{73}$ Tal concentración de poder no fue, insistimos, el resultado de acciones individuales, sino el fruto de una estrategia bien llevada por el grupo clerical que estuvo muy cerca de los arzobispos y de los ascensos en el alto clero entre 1700 y 1730.

${ }^{71}$ AGI, Indiferente, 2863, libro 4. El nombramiento tiene fecha de 13 de febrero de 1704.

72 A GI, Indiferente, 2863, libro 4. Otros cargos menores, más de tipo honorífico, fueron el de examinador sinodal y el de consultor de la Inquisición. Además fue designado capellán de las carmelitas descalzas del convento de San José y llegó incluso a ser abad de la congregación de sacerdotes de San Pedro, cargo honorífico de la confraternidad sacerdotal más importante del arzobispado.

${ }^{73}$ AGN, Bienes Nacionales, 739, exp. 9, carta de 24 de julio de 1723. 
De la Universidad al bajo clero parroquial: los indios bachilleres

En contraste, las expectativas para los indios en las instituciones y en las profesiones del ámbito español eran muy limitadas. El panorama era complicado para ellos pues además de seguir siendo considerados de menor calidad social, también carecían de los recursos económicos y relaciones necesarias para emprender una carrera prestigiada como la descrita antes. Aun cuando un indio cubriera los requisitos formales de estudios y origen social exigidos por las instituciones educativas y eclesiásticas, los valores sociales defendidos por los grupos dominantes de la sociedad eran un impedimento. Ni siquiera los hijos de caciques, aun con sus probanzas de legitimidad y limpieza de sangre, se salvaban de ser menospreciados en los colegios o en la Universidad, en donde sus condiscípulos españoles negaban tener sangre india en ese mismo tipo de probanzas. ${ }^{74}$ De hecho, los indios participaban muy poco de la vida académica de la Universidad, a juzgar por los actos, provisiones de cátedras y demás hechos que se tienen registrados en el archivo universitario. Los pocos que lo lograron tuvieron que pasar años en las ciudades episcopales, opositando a los curatos vacantes y cultivando buenas relaciones con el alto clero. A ello habría que agregar la falta de "conveniencias" de los indios; es decir, lazos de amistad o de patronazgo, de autoridades y grupos académico clericales de poder. Es

${ }^{74}$ AHSCM, Sección de Informes de colegiales. En el ramo Universidad, del AGN, pueden revisarse los expedientes de grado de doctor en ese sentido. 
comprensible entonces que el destino más común de los indios bachilleres fuese el de vicarios auxiliares o tenientes de curatos rurales, pues su ascenso a curas titulares era excepcional. Por supuesto que tal horizonte -nada halagüeño- lo compartían con clérigos de otras calidades, que igualmente tenían pocas probabilidades de ascender pero sí mucho que hacer en el campo, como lo aceptó el arzobispo Rubio y Salinas en 1764:

[...] de ella, por lo que les queda muy poco tiempo para el estudio y aun para el preciso descanso. Su instrucción generalmente se limita a la gramática y materias morales, como a la perfecta comprensión de los idiomas. Y, a proporción de sus talentos, virtud y tiempo que han administrado, se les acomoda en curatos de su idioma y en las parroquias en que fallecen los curas propios, hasta que llegue el caso de la provisión y entre tanto perciben íntegramente las obvenciones y emolumentos del beneficio y pagan a sus ayudantes. A éstos se destina para coadjutores de los curas enfermos o impedidos por alguna causa y en este ejercicio concluyen su carrera gustosamente. ${ }^{75}$

La existencia de indios como curas titulares no era, pues, común. En 1760, de 103 curas propietarios del arzobispado de México, sólo 7 tenían esa calidad. ${ }^{76}$ En la década de 1790, en algunos informes se mencionaba a 19 curas y ayudantes indígenas. El problema es que la documentación está incompleta y es difícil hacer un mejor cálculo. ${ }^{77}$

\footnotetext{
75 AGI, México, 2549.

76 TAYlor, Ministros de lo sagrado, t. I, p. 124.

77 TaYlor, Ministros de lo sagrado, t. I, p. 141, n. 80. Lo mismo ocurre cuando consultamos el padrón del arzobispado de México de 1777, en donde sólo se consignan tres indios clérigos en los curatos de Hueypoxtla,
} 
La trayectoria de los indios en la Iglesia puede representarse por Juan Faustino Xuárez de Escovedo, descendiente de los caciques del pueblo de la Candelaria, parroquia de Santa Cruz, ubicada al sureste de la ciudad de México, y quien llegó a ser un presbítero muy activo, bien conocido en la curia, pero que luego de casi dos décadas no había logrado aún un nombramiento medianamente aceptable. ${ }^{78}$

Xuárez Escovedo estudió entre 1711 y 1729: primeras letras en el Colegio de San Gregorio; latín en el convento de la Merced y el seminario conciliar de México; retórica y artes en este mismo colegio y en la Universidad, así como teología también en esta última. Durante esos años tuvo un desempeño ordinario, dedicándose a cumplir las exigencias académicas de los colegios y la Universidad, lo cual le llevó a conseguir en 1725 el grado de bachiller en Filosofía, el más común del clero secular, y en 1729 el de bachiller en Teología.

Más importante para Juan Faustino fue el aprendizaje del náhuatl en la Universidad, básico para su trayectoria en el clero secular, ${ }^{79}$ en donde se ordenó de presbítero en 1730 , en condiciones de pobreza ante la falta de algún empleo o renta, ${ }^{80}$

Tlachichilco y Zontecomatlan respectivamente, lo cual a todas luces no es creíble en vista de lo expresado en páginas anteriores. Véase AGN, Padrones, Padrón del arzobispado de México. 1777.

78 AGN, Bienes Nacionales, 199, exp. 12. Relación de méritos.

79 AGN, Bienes Nacionales, 199, exp. 12: “El día 27 de febrero del año de 1726 recibió certificación de haber cursado la cátedra de la lengua mexicana en la Real Universidad desde el año de 24, en donde aprendió dicha lengua con aplauso de su catedrático el reverendo padre maestro fraile Jacinto González, religioso de Nuestra Señora de la Merced”.

${ }^{80}$ Xuárez Escobedo narra en su relación de méritos que en 1730 tuvo que ir caminando hasta la ciudad de Puebla para ordenarse de presbítero: "[...] caminando con la abatida enfermedad de la pobreza hasta la 
como podía ser la de una capellanía. ${ }^{81}$ Retirado de la academia y de la búsqueda de los grados mayores, nuestro personaje buscó en cambio obtener ingresos seguros más que emprender una carrera eclesiástica ascendente. Este tipo de intereses se combinó con la política de la mitra, consistente en que los presbíteros recién ordenados adquirieran experiencia en forma práctica; es decir, ser enviados como ayudantes, confesores o predicadores con curas experimentados. Quienes se destacaban y estaban bien relacionados en la curia y en el cabildo catedralicio podían esperar pronto un curato en propiedad; quienes no tenían ni una ni otra opción podían seguir indefinidamente en esos cargos subalternos. Juan Faustino es ejemplo de este sector: entre 1731 y 1749 tuvo tres actividades en la administración parroquial, siempre subordinado a curas propietarios: confesor en castellano y náhuatl, predicador y ayudante o coadjutor temporal. Durante esos años cambió de parroquia hasta en 10 ocasiones: 1731-1733: Iztapalapa y Tizayuca; 1734-1735: Coscatlán, en la región cálida de la Huasteca; 1736-1738: Amatepec y Tlatlaya; 1739: Iztapalapa otra vez; 1740: Churubusco; 1741-1742: Tenango del Valle; 1742:

ciudad de la Puebla en donde concluyó el anhelo de sus deseos de verse presbítero aunque indigno”. AGN, Bienes Nacionales, 199, exp. 12.

${ }^{81}$ Por los mismos años, un joven clérigo de la misma edad de Juan Faustino, bien acomodado, podía vivir cómodamente con la renta de dos o más capellanías, esperando en su casa un buen cargo, sin necesidad de tocar puertas para pedir cualquier ingreso que mitigara sus necesidades. Un ejemplo: en 1725, el bachiller Diego de Morales, presbítero, vivía de la renta de 3 capellanías en propiedad, cuyo capital total era de 8000 pesos, el valor de una hacienda mediana, y que le daban una renta anual de 400 pesos, más de lo que muchos ayudantes de cura podían esperar. AGN, Bienes Nacionales, 752, exp. 21. 
Tenancingo; 1743: Iztapalapa por tercera ocasión; 17431744: vicario en Xochialicpa, en la sierra; 1745-1749: coadjutor y juez eclesiástico de Chilpancingo y Zumpango del Río. En todos ellos, Juan Faustino desarrolló múltiples actividades: predicó, confesó, administró todos los sacramentos, fundó varias cofradías, tanto de indios como de "gente de razón” o españoles, reedificó iglesias y capillas en ruinas, compró nuevos ornamentos para los templos y estableció escuelas parroquiales para los niños. Persiguió a indios “idólatras” e igual casó a parejas de “amancebados”. Sin duda que Xuárez representa al ayudante ideal para los curatos de tierra caliente, los menos apetecidos por la clerecía.

\section{REFLEXIONES FINALES}

Desde la perspectiva de los doctores del claustro que gobernaban a la Real Universidad de México la corporación estaba sólo integrada por letrados de distinguida cuna, alejados de la "infeliz constitución de los indios". ${ }^{82}$ En 1777, los catedráticos y los doctores, quienes se asumían como "la Universidad”, volvieron a recordar tal principio al rey, ante la perspectiva de perder la posibilidad de acceder a los altos cargos. En el discurso honorífico, "la Universidad” ignoró la presencia de estudiantes y graduados de condición social baja, según los valores de la época.

En los hechos, desde el siglo Xvi se dio una diversificación social que continuó en el siguiente. Si bien en sus orígenes esta institución fue pensada para los descendientes de conquistadores y colonizadores españoles, para el siglo XVIII

${ }^{82}$ AGN, Universidad, 25, ff. 199v.-207v. 
la población universitaria distaba mucho de ser la corporación de españoles que sus doctores deseaban. El discurso apologético debe interpretarse más como una retórica política que como una descripción de la población universitaria. No obstante, en la vida cotidiana de la Universidad, los rectores y el claustro de doctores tuvieron que afrontar esa nueva realidad social. Así, desde principios del siglo xviII se fue construyendo un principio de tolerancia, tanto por la monarquía como por los juristas universitarios, quienes buscaron interpretaciones para conciliar lo dispuesto por la constitución 246 con la diversidad social del estudiantado.

No obstante la mayor apertura social de las escuelas universitarias, ello no significó una igualdad social. Podían coincidir en los diferentes espacios universitarios hijos de pudientes comerciantes o poderosos oidores, sobrinos de altos eclesiásticos con hijos de modestos labradores o maestros de algún arte mecánico, pero también con alguno que otro hijo de cacique, o de un mulato barbero o de una familia mestiza de vendedores viandantes. Podían compartir aulas, funciones religiosas en la capilla, exámenes de grado o certámenes poéticos, pero las distancias sociales no desaparecían. Ello se reflejaba con mayor claridad cuando los estudiantes finalizaban sus estudios, se graduaban y comenzaban una trayectoria pública. En esta fase, los graduados echaban mano no sólo de sus méritos académicos, sino de sus relaciones familiares, de amistad y de patrocinio, si es que las tenían. Los casos expuestos del arcediano José de Torres y Vergara, por un lado, y del ayudante de cura, José Xuárez de Escovedo, por el otro, ejemplifican los factores que explican el ascenso del primero al alto clero del arzobispado así como las limitantes de un clérigo indio para poder 
seguir el mismo camino. Los recursos y relaciones de Torres Vergara en la Universidad, en los grupos clericales en ascenso de la capital, así como su cercanía con el cabildo catedralicio y la mitra eran casi inexistentes para la mayoría de los clérigos de orígenes sociales bajos.

\section{SIGLAS Y REFERENCIAS}

AGN Archivo General de la Nación, México.

AGI Archivo General de Indias, Sevilla, España.

AHSCM Archivo Histórico del Seminario Conciliar de México, México.

Aguirre Salvador, Rodolfo

Por el camino de las letras. El ascenso profesional de los catedráticos juristas de la Nueva España. Siglo XvIII, México, Universidad Nacional Autónoma de México, 1998.

El mérito y la estrategia. Clérigos, juristas y médicos en Nueva España, México, Universidad Nacional Autónoma de México, Plaza y Valdés, 2003.

Aguirre Salvador, Rodolfo (coord.)

Carrera, linaje y patronazgo. Clérigos y juristas en Nueva España, Chile y Perú (siglos XVI-XVIII), México, Universidad Nacional Autónoma de México, Plaza y Valdés, 2004.

"Algunas problemáticas sociales del estudiantado de la Real Universidad de México en el siglo xviri”, en Alvarado y Ríos (coords.), 2011, pp. 135-158.

"Los registros de grado de los colegiales de la Nueva España en la Real Universidad de México", en Cuadernos del Archivo Histórico de la UNAM, 14, 2004, pp. 145-183.

"El arzobispo de México Ortega Montañés y los inicios del subsidio eclesiástico en Hispanoamérica, 1699-1709", en CERvantes, Tecuanhuey y Martínez (coords.), 2008, pp. 253-278. 
Un clero en transición. Población clerical, cambio parroquial y política eclesiástica en el arzobispado de México, 1700-1749, México, Instituto de Investigaciones sobre la Universidad y la Educación, Bonilla Artigas Editores, Iberoamericana Vervuet, 2012.

Alberro, Solange

Inquisición y sociedad en México, 1571-1700, México, Fondo de Cultura Económica, 1980.

Alberro, Solange y Pilar Gonzalbo

La sociedad novohispana. Estereotipos y realidades, México, El Colegio de México, 2013.

Alvarado, María de Lourdes y Rosalina Ríos (coords.)

Grupos marginados de la educación en América Latina, siglo XIX y XX, México, Instituto de Investigaciones sobre la Universidad y la Educación, Bonilla Artigas Editores, 2011, pp. $135-158$.

Álvarez, Luis Alonso

"Los señores del Barangay. La principalía indígena en las Islas Filipinas, 1565-1789: viejas evidencias y nuevas hipótesis”, en Menegus y Aguirre (coords.), 2005, pp. 355-406.

Carrillo, Rubén

"Asia llega a América. Migración e influencia cultural asiática en Nueva España (1565-1815)”, en Asiadémica, 3 (ene. 2014), pp. 81-98.

Cervantes, Francisco Javier, Alicia Tecuanhuey y María del Pilar MARTÍnez (coords.)

Poder civil y catolicismo en México. Siglos XVI-XIX, Benemérita Universidad Autónoma de Puebla, Universidad Nacional Autónoma de México, 2008, pp. 253-278.

Chacón Jiménez, Francisco

"Estructuración social y relaciones familiares en los grupos 
de poder castellanos en el Antiguo Régimen. Aproximación a una teoría y un método de trabajo", en Dedieu, Castellano y López-CORdón (coords.), 2000, pp. 355-362.

Chocano Mena, Magdalena

La fortaleza docta. Élite letrada y dominación social en México colonial [siglos XVI-XVII], Barcelona, Edicions Bellaterra, 2000.

Estatutos y constituciones reales de la imperial y regia Universidad de México, México, Imprenta de la Vda. de Bernardo Calderón, 1688.

\section{Claustros y estudiantes}

Claustros y estudiantes, prólogo de Mariano Peset, Valencia, España, Universidad de Valencia, 1989, 2 volúmenes.

Dedieu, Jean Pierre, Juan Luis Castellano y María Victoria López-CORDón(coords.)

La pluma, la mitra y la espada: estudios de historia institucional en la Edad Moderna, Madrid, Marcial Pons, 2000.

FausT, Katherine

"Las redes sociales en las ciencias sociales y del comportamiento”, en Gil Mendieta y Schmidt (eds.), 2002, pp. 1-14.

Ganster, Paul

"Miembros de los cabildos eclesiásticos y sus familias en Lima y la ciudad de México en el siglo xvin", en Gonzalbo (coord.), 1991, pp. 149-161.

"La familia Gómez de Cervantes. Linaje y sociedad en el México colonial”, en Historia Mexicana, xxxi: 2 (122) (oct.dic. 1981), pp. 197-232.

García, Elisa Itzel y Marcela Rocío García

III Concilio y Directorio, libro 1, título IV, en MarTínez (coord.), 2004, disco compacto. 
Gil Mendieta, Jorge y Samuel Schmidt (eds.)

Análisis de redes. Aplicaciones en ciencias sociales, México, Universidad Nacional Autónoma de México, 2002.

Gonzalbo, Pilar

Familia y orden colonial, México, El Colegio de México, 1998.

Historia de la educación en la época colonial. La educación de los criollos y la vida urbana, México, El Colegio de México, 2008.

Historia de la educación en la época colonial. El mundo indígena, México, El Colegio de México, 2008.

Gonzalbo, Pilar (coord.)

Familias novohispanas. Siglos XVI al XIX, México, El Colegio de México, 1991.

González González, Enrique

"Legislación y poderes en la universidad colonial de México (1551-1668)", tesis doctoral, Valencia, Universidad de Valencia, 1990.

"Mecenazgo y literatura. Los destinos dispares de Juan de Narváez y Sigüenza y Góngora", en Aguirre Salvador (coord.), 2004, pp. 17-38.

Martínez López-Cano, Pilar (coord.)

Concilios provinciales mexicanos. Época colonial, México, Universidad Nacional Autónoma de México, 2004, disco compacto.

Menegus, Margarita

"Dos proyectos de educación superior en la Nueva España en el siglo xvi. La exclusión de los indígenas de la Universidad", en La Real Universidad de México, 1987, pp. 83-89.

Menegus, Margarita (coord.)

Universidad y sociedad. Grupos de poder en el siglo XVIII, México, Universidad Nacional Autónoma de México, Plaza y Valdés, 2001. 
Menegus, Margarita y Enrique Gonzalez (coords.)

Historia de las universidades modernas. Métodos y fuentes, México, Universidad Nacional Autónoma de México, 1995.

Menegus, Margarita y Rodolfo Aguirre

Los indios, el sacerdocio y la Universidad en Nueva España. Siglos XVI-XVIII, México, Universidad Nacional Autónoma de México, Plaza y Valdés, 2006.

Menegus, Margarita y Rodolfo Aguirre (coords.)

El cacicazgo en Nueva España y Filipinas, México, Universidad Nacional Autónoma de México, 2005.

Oropeza Keresey, Deborah

"La esclavitud asiática en el virreinato de la Nueva España, 1565-1673”, en Historia Mexicana, LXI: 1 (241) (jul.-sept. 2011), pp. 5-57, http://redalyc.org.www.redalyc.org/articulo.oa?id=

Pavón Romero, Armando

"Universitarios y universidad en México en el siglo xvi", tesis de doctorado en historia, Valencia, España, Universidad de Valencia, 1995.

Pavón Romero, Armando y Clara Inés Ramírez González (comps.)

El catedrático novohispano: oficio y burocracia en el siglo XVI. Serie: La Real Universidad de México. Estudios y textos IV, México, Universidad Nacional Autónoma de México, 1993.

Pérez Puente, Leticia

"El surgimiento de una universidad de doctores. México, 1600-1654”, tesis de maestría en historia de México, México, Universidad Nacional Autónoma de México, 1996.

Peset, Mariano, María Fernanda Mancebo y María Fernanda Peset "El recuento de los libros de matrícula de la Universidad de México”, en M. Peset (comp.), Universidades españolas y 
americanas. Época colonial, Valencia, Generalitat Valenciana, 1987, pp. 433-443.

Ramírez González, Clara Inés

"La Real Universidad de México en los siglos xvi-Xvir. Enfoques recientes”, en Menegus y GonzÁlez (coords.), 1995, pp. 83-94.

Ramírez González, Clara Inés y Armando Pavón Romero

"De estudiantes a catedráticos. Un aspecto de la Real Universidad de México en el siglo xvi”, en Claustros y estudiantes, vol. II, pp. 279-290.

La Real Universidad de México

La Real Universidad de México: Estudios y textos, vol. 1. Historia de la universidad colonial: avances de investigación, México, Universidad Nacional Autónoma de México, 1987, 2 volúmenes.

Recopilación

Recopilación de leyes de los reynos de las Indias. 1681, México, Escuela Libre de Derecho, Miguel Ángel Porrúa, 1987, facsímil de la de 1681 .

SÁnchez Santiró, Ernest (ed.)

Padrón del arzobispado de México 1777, México, Secretaría de Gobernación, 2003.

TAYLOR, William B.

Ministros de lo sagrado. Sacerdotes y feligreses en el México del siglo xviII, México, El Colegio de México, El Colegio de Michoacán, 1999 , t. I.

Wobeser, Gisela von

El crédito eclesiástico en la Nueva España. Siglo XVIII, México, Universidad Nacional Autónoma de México, 1994. 
